Published in International Journal of Organizational Analysis, 2016, vol. 24, no 3, pp. 516-531, which should be cited to refer to this work

\title{
SENSEMAKING OF ORGANIZATIONAL INNOVATION AND CHANGE IN PUBLIC RESEARCH ORGANIZATIONS
}

\section{Author Details:}

Carlos Martin-Rios

Ecole hôtelière de Lausanne, HES-SO // University of Applied Sciences Western Switzerland

Route de Cojonnex 18

1000 Lausanne; Switzerland

Corresponding author: [Carlos Martin-Rios]

[carlos.martin-rios@ehl.ch]

NOTE: affiliations should appear as the following: Department (if applicable); Institution; City; State (US only); Country. No further information or detail should be included

\section{Acknowledgments (if applicable):}

I want to thank two anonymous reviewers for their comments on earlier drafts of this paper. Also, I want to thank Charles Heckscher and Cesar Gonzalez who have provided inspiration and contributed ideas on selected issues in the paper. An earlier version was presented at the Mini-EURAM Workshop on Organizational Innovation (Rotterdam, 2012).

\section{Biographical Details (if applicable):}

Carlos Martin-Rios is professor at the École hôtelière de Lausanne, Switzerland, and managing director of the Center for Management Innovation (Madrid, Spain). His research interests are concerned with organizational innovation and renewal with an emphasis on knowledge-intensive work settings. His recent work has been published in Journal of Management Inquiry, Journal of Business Research, Human Resource Management, or Research in Personnel and Human Resource Management.

\section{Structured Abstract:}

Purpose - The purpose of this paper is to examine through a sensemaking lens the transforming nature of scientists' work role in Public Research Organizations (PROs) resulting from organizational innovations in the form of collaborative culture.

Design/methodology/approach - Based on a symbolic-functionalist theory of work role transition, the paper uses interview data from a case study to explore scientists' sensemaking of work role change.

Findings - Work role transition and identity processes amongst scientists in traditional PROs reveal tensions regarding organizational restructuring, to the extent that organizational innovations changing scientific work conflict with organizational norms, procedures, and reward structures in hierarchical, bureaucratic PROs.

Research limitations/implications - As the paper is founded on only one case study, further research should be carried out on the difficulties involved in transforming the nature of the scientific work role and the way scientists recognize, contradict, and make sense of changes.

Originality/value - The novelty of this paper is in the un-discussed role of organizational innovations in enabling new work roles for scientists in public research centers and how scientists make sense of and react to these innovations. Therefore, this paper could be beneficial for PROs facing pressure to restructure.

\section{Keywords:}

Public research organization; collaborative culture; process change; work role transition; organizational innovation

Article Classification: Research Paper

For internal production use only

Running Heads: Sensemaking in a Public Research Organization 


\section{SENSEMAKING OF ORGANIZATIONAL INNOVATION AND CHANGE IN PUBLIC RESEARCH ORGANIZATIONS}

\section{Introduction}

The need for sustainable innovation and change reflects a way in which public services overcome inertia and respond to changes in the external environment. Organizational or administrative innovation, conceptualized as a way in which organizations respond to environmental challenges by the creation, development and implementation of a new organizational method or practice that has an impact on the organization's overall success (Damanpour, 1991; Damanpour et al., 2009), can serve as an important enabler of change in highly rigid work environments, as often characterized in public service organizations, such as scientific or public research organizations (hereinafter, PRO). Scientific organizations or PRO are defined as government-funded research organizations that include non-profit research institutions, government agencies, and laboratories. It is commonly assumed that PROs carry out basic scientific research, while private companies are engaged in more applied efforts (Merton, 1973; Nelson, 1990). However, nowadays trends in greater economic liberalization, less public funding and greater pressure for tangible outputs (e.g. patents), have blurred the boundaries between the spheres and new types of independent public research centers have emerged that depart from the civil service model to adapt management practices from the private sphere. Traditional PROs are therefore increasingly required to become service-oriented, in the sense that they are expected to offer products, processes and performance. These trends toward increased complexity have wide-ranging consequences on the way research scientists are managed. Therefore, PROs are a model case study of the growing pressure on public services toward greater efficiency, public salience and accountability.

Since the early 1980s, the New Public Management (NPM) paradigm has permeated the practices of public organizations in Western Europe and the USA as well most industrialized countries. Proponents 
of the NPM paradigm posit that these new PROs are better suited to address institutional (i.e., political, administrative and legal) environment pressures in which public service providers (in this case, PROs) operate. However, there are also limits to the radical restructuring of public institutions guided by private sector models (Fernandez and Rainey, 2006; McNulty and Ferlie, 2004). In this sense, sources of organizational innovation promoted from the inside are deemed amenable to organizations of this kind (Damanpour, 1991; Simpson and Powell, 1999; Salge, 2011).

There are also consequences on how scientists make sense of the restructuring of PROs guided by private sector models. The transition of PROs and, broadly, public service organizations toward postbureaucratic or collaborative types of organization presents intrinsic difficulties, particularly those associated with the way individuals recognize, contradict, and make sense of changes in their work role and identity (Josserand et al., 2006; Brunton and Matheny, 2009). The limited scope of knowledge about professional role transition in public science theory may be contributing to scientists' unfamiliarity with and lack of preparedness for organizational innovations designed to promote change. Research should thus establish a link between external pressure and innovation, examining how researchers in PROs actually think, experience, and react to role transitions. Significant questions remain unanswered, specifically: How do scientists in PROs make sense of organizational innovations due to external (institutional, political, administrative) pressures?

Building on the work of Nicholson (1984), I show how a symbolic interactionist theory of work role transition is especially useful in explaining identity shifts due to the implementation of significant changes to the culture and practice. Symbolic interactionism argues that reality is constructed as a social interaction reality. Organizational members frame meaning to make sense of the construed realities (Daft and Weick, 1984; Hernes and Maitlis, 2010; Maitlis, 2005). This study focuses on a governmentfunded research institute under the administrative authority of the Spanish government, which, due to 
funding and accountability pressures, launched an innovation initiative to formulate a collaborative, multidisciplinary organizational culture. However, public research policies and work roles in Spain (and Europe) are strongly based on the concept of knowledge areas or disciplines, and although the idea of interdisciplinarity is often praised, an actual interdisciplinary implementation is unlikely to survive in an environment built for traditional, discipline-oriented norms and incentives for scientists.

The next section first presents the conceptual framework to account for the blurring boundaries between public and private research centers, and then looks at scientists' responses to changes in work

role as symbolic interaction. The next section presents some background on the Spanish PRO focus of this study and the qualitative data collection and analysis. Finally, discussion of findings and implications for the study of work role transitions in national science systems are offered.

\section{Literature review}

Public science organizations are a heterogeneous group of research performing centers that benefit from high shares of public funding (OECD, 2011). The literature on PROs distinguishes between public universities, traditional overarching PROs, such as the National Centre for Scientific Research (CNRS) in France, the National Research Council (CNR) in Italy, the Spanish National Research Council (CSIC) in Spain and the Max Planck Society (MPG) in Germany, and mixed or independent public research centers that have emerged since the late 1990s and are characterized by more flexible organizational arrangements. (Cruz-Castro et al., 2012). I give special attention to traditional PROs in our analysis, focusing on scientists' understanding and reaction to organizational innovations. External pressures toward a more applied type of PROs must have consequences on the way scientists make sense of organizational innovations and the consequences in their work role transition — both in their daily duties and their professional identity at large.

New Public Management and the pressure toward postbureaucracy in PROs 
In a time of evolving policy paradigms, institutional pressure toward greater accountability and increasing competition for public resources falls squarely on PROs.

According to Ferlie et al. (1996), NPM involves introducing the "three Ms" into public services: markets, managers and measurement. Underlying is the belief that the use of market-oriented management methods will increase the efficiency of public services and institutions (Ferlie et al., 1996). The NPM literature has pointed to the blurred boundaries between public and private spheres, which has been called 'publicness' (Perry and Rainey 1988; Rainey and Bozeman 2000). Publicness is a multidimensional concept that points to the constant influence of government authority. Bozeman and colleagues have analyzed diversity among research centers (Bozeman 1987; Bozeman and Crow 1990; Crow and Bozeman 1998) to reveal that boundaries between public and private organizations are more permeable than before. New, mixed or independent public research centers have emerged that are not tied to the civil service model and are oriented to do research that is both excellent and use-inspired (Martinez et al., 2013).

The use of market-oriented management methods of NPM has recently found its way into PROs in many European countries. Researchers working at these new PROs are hired with private labor law contracts; contract extensions depend on evaluation results, and there is a high turnover of staff (Bozeman and Boardman, 2003). Based on these methods, PROs are expected to adapt to changes by conforming to isomorphic pressures toward more efficient and legitimate organizations. According to Sanz-Menendez and Cruz-Castro, (2003) a large share of PROs have progressively conformed to a funding strategy based on diversifying sources and increasing competitive public funding. Traditional PROs face mounting competition for funding from new independent public research centers (CruzCastro et al., 2012). It can therefore be expected that innovations in culture and management patterns will take place among traditional PROs as well. The bureaucratic organizational system of PROs, which 
was based on a clear professional path for civil servants, a reduced number of hierarchical layers, and standardized compensation and evaluation practices, is subject to increasing debate and reform (Clanon, 1999; Mallon et al., 2005; Simpson and Powell, 1999).

Yet, the impact that these new types of management methods have on science policy's demands toward traditional PROs has been less studied in the literature.

\section{Organizational Innovation in PROs}

The need for innovation reflects the way in which organizations overcome inertia and respond to changes in the external environment. Innovation studies have traditionally been linked with technological change, usually related to manufacturing activities, and until recently, organizational or management innovation has received little systematic attention (Armbruster et al., 2008; Birkinshaw et al., 2008; Hipp and Grupp, 2005; Martin-Rios, 2014; Parga et al., 2014). Recent developments in the study of organizational renewal have revealed the potential of organizational innovations for the design and improvement of internal processes and values.

Organizational innovation concerns organizational adaptation to respond to technological, social and market-related challenges (Damanpour et al., 2009). It is the less discrete, more intangible and organization-specific part of innovation (Armbruster et al., 2008). The feature that distinguishes organizational innovation from other organizational changes is the implementation of an organizational method that has not been used before in the organization and that is the result of strategic decisions (OECD, 2005). Hence, successful organizational innovation is challenging as it questions existing practices and processes, as well as ingrained assumptions on the way things are (Damanpour, 1991). It emphasizes innovation as a critical process of PROs unleashing organizational adaptation by means of introducing a new management practice, process, structure, or technique into the organization with the ultimate purpose of improving the effectiveness of the adopting PRO. 
Nevertheless, there is no clear definition of the way PROs replace the structures, practices, values and behaviors of the 'old approach' with new, post-bureaucratic and collaborative work systems (Martin-Rios, 2015). Since structural changes are hard and costly to implement, it is expected that certain PROs will attempt alternative avenues such as innovations in infrastructure- the softer part of organizing, including work culture and values.

In particular, growing pressure on science toward collaborative and multidisciplinary research efforts (Jones et al., 2008) is reflected in the promotion of collaborative organizational culture (Heckscher and Martin-Rios, 2013; Martin-Rios-Heckscher, 2014). The notion of collaborative culture represents a departure from norms and values in traditional, bureaucratic settings (Heckscher, 2007). It addresses the diverse pool of knowledge, skills, and experience brought by people from different spheres to the collaborative effort, and therefore may have an impact on work roles and engagement (Adler $e t$ al., 2008; Beer, 2011). It is suggested that organizations pursuing a collaborative culture place strong emphasis on aligning the standard bureaucratic interest of individual performance with the need to build collaborative work relationships and shared professional values as they seek to adopt greater emphasis on common purpose and outcomes in order to thrive. The underlying notion involves developing collaborative values and improving the common purpose, efficiency and accountability of PROs, not just through bureaucracies but also through new organizational values, norms and roles.

\section{Sensemaking of role transition}

A symbolic interactionist perspective on scientists' role transition provides an appropriate lens for examining public researchers' understanding of their new work roles. As predicted in role transition theory, changes in organizational culture may have a profound impact on role requirements. Organizational and individual discontinuity and change yield to a transition between old and new job roles, requiring adjustment to meet the role requirements of the new environment (Nicholson, 1984). A 
symbolic interactionist perspective presupposes that scientists' understanding of their work roles is based on the meaning those roles have for them; these meanings are derived from social interaction and modified through interpretation (Ashforth, 2000; Hernes and Maitlis, 2010; Maitlis, 2005).

Work role transition makes it possible to analyze how sensemaking unfolds. The process of sensemaking refers to the way in which people understand, organize and make sense of equivocal inputs and enact this sense back into the world to make that world more orderly (Weick et al., 2005). With this approach, Weick aims to move organizational studies "from its focus on structure (organization) to process (organizing)" (Hatch and Yanow, 2002, p.78, emphasis in original). The core idea is that "reality is an ongoing accomplishment that emerges from efforts to create order and make retrospective sense of what occurs" (Weick, 1993, p.628). As scientists make sense of the new reality that follows from an organizational innovation such as the establishment of new organizational culture, they create an understanding and begin to act in a way that complies with this understanding (Stensaker and Falkenberg, 2007).

\section{Methodology}

\section{Data collection}

This paper adopts a longitudinal case study methodology (Van de Ven and Huber, 1990) on a government-funded research institute, HumScience (a pseudonym) under the administrative authority of the Spanish government (the Ministry of Science and Innovation). Given that perceiving, interpreting, believing, and acting as a result of organizational innovations are gradual processes, our research draws on a longitudinal study to construct a detailed process history of how researchers make sense out of the change that is occurring. To do so, it follows a classic qualitative approach to organizational inquiry (Yin, 1994). Over a five-year period between 2008 and 2012, I visited the facilities on multiple occasions in order to carry out in-depth interviews and focus groups, and collect documentary data. 
Fieldwork came to an end when cultural change was consolidated and ingrained in HumScience as a whole.

This institute was selected because of its potential to provide insights into the individual sensemaking process and the way in which researchers interpret changes in their work role as a result of organizational innovation. In late 2008, the organization embarked on a wide organizational change initiative with the aim of articulating a formal strategic mission (in terms of setting organizational objectives), addressing issues pertaining to organizational structure, culture and decision-making, set apart from the bureaucratic constraints commonly found in public administration. This transformation process presented us with a unique opportunity to observe a natural experiment in internally-driven organizational innovation and redesign.

Data were drawn from in-depth interviews, specific organization documents (a review of project reports and internal memos, training material, employee surveys and publications) and publicly available literature on the organization. The qualitative approach provided a rich and comprehensive view of the innovation initiative. Process, fine-grained qualitative data for this study involved multiple levels and units of analysis (Strauss and Corbin, 1998). On the one hand, data collected at the organization level were mainly obtained through HumScience's leadership team and senior researchers, as well as researchers responsible for certain areas of the organization (e.g. head of the publications department or project leaders in certain fields of specialization). They provided valuable information to examine the sequence of events over time, how reform of organizational culture unfolded, and how to identify process patterns. On the other hand, sensemaking regarding changes in work roles and identity were obtained through interviews with the organizational members themselves. Information collected from interviews was obtained by interviewing 20 key participants on-site at HumScience. Over the five-year period, interviewees were interviewed on more than one occasion or even multiple times. I interviewed 
all of the members participating in innovation initiatives, together with several representative senior and junior scientists, in order to elucidate how researchers made sense of (recognized, contradicted or negotiated) the processes of creating, implementing, and assessing the subjective impact of the emerging collaborative culture on their work roles. Additionally, numerous informal conversations took place over the four-year period of fieldwork.

All requests for interviews were answered positively and nobody declined to participate. Participation was voluntary. Interviewees were assured of the anonymity and confidentiality of their responses. Interviews ranged roughly from 60 to 90 minutes. They were digitally recorded, with permission, and transcriptions were made of all relevant portions. A semi-structured interview template was used to guide the research, but the template was not followed strictly, and interviewees were prompted to talk freely about whatever seemed important to them. Interviewees were prompted to describe the work content in terms of how individual participation was promoted, assessed and rewarded, similarities and differences between work content and nature of those differences, their perceived effectiveness of the different organizational practices in place, and drawbacks they found. There were also questions regarding the evolving organizational culture and support systems put in place to cope with changes in work demands, control and stress factors, their views about the change process itself, and their personal expectations regarding the future.

\section{Data treatment}

Overall, the sensemaking process of the 'messy' information that was collected (Weick, 1993) was attempted by: (1) contrasting the prior and emerging organizational culture in HumScience; and (2) finding which elements of change elicited people's reactions and the reasons for them. The qualitative approach provided a rich and comprehensive view of changes in work roles in the eyes of its organizational members. Data were framed by the symbolic-interactionist theory of work role transition 
(Charon, 2009) and involved a close examination of the experiences and meaning-making activities of organizational members. A process theorization approach highlights the relevance of work role change and its consequences in terms of sensemaking (Langley, 1999; Langley et al., 2013).

This research adopts Miles and Huberman's (1994) three stage coding process, involving open coding, axial coding, and selective coding to identify and explore understandings and perceptions related to the change initiative launched between 2008 and 2012. An initial coding scheme of the data was generated from the interview transcriptions and focus groups (400 pages) and from notes about the observations and informal interviews. Utilizing the initial coding scheme, a research assistant coded a sample from 5 interviews to assess the validity of this process.

The researcher then generated a list of 38 descriptive codes about how organizational members made sense of changes in their work roles resulting from introduction of a collaborative organizational culture. Next, the author sorted and grouped the initial descriptive open codes into more analytical categories (axial coding) that would explain the processes of recognizing, contradicting, or negotiating the emerging work role. The researcher compared and contrasted individual codes, eliminating unnecessary codes and merging overlapping ones. Finally, the researcher analyzed and grouped these categories into larger themes that would serve as the foundation of the overall theoretical framework to understand how researchers in a PRO made sense of (recognized, contradicted or negotiated) the researcher's work role resulting from organizational innovations in the form of collaborative culture.

---- Insert Table 1 about here ----

\section{Case study findings}

The Spanish National Research Council (Consejo Superior de Investigaciones Científicas, CSIC) is a government-funded research organization under the administrative authority of the Spanish government (the Ministry of Science and Innovation). It is formally organized as a collection of over 
130 research institutes, each of which specializes in a particular area of knowledge. Our research case involves HumScience, one of the youngest institutes of the CSIC engaged in basic, non-applied research in the field of the humanities. In late 2008 , the organization embarked on a broad organizational innovation initiative with the aim of managing the organization in a more interdependent way and move away from the bureaucratic constraints commonly found in public administration. This transformation process presented us with a unique opportunity to observe a natural experiment in internally-driven organizational innovation.

In terms of formal organization, HumScience was originally organized around the logic of scientific bureaucratic organizations - formal, highly centralized at the top level channels of decision-making and communication, coupled with standard personnel practices. As a result, it was likely that it would become more complex as the areas of research and the number and quality of projects increased. Beyond that, the research team operated in a rather informal way. This type of relaxed, informal culture of 'free agents' offered advantages to self-motivated researchers, such as allowing disciplinary autonomy from outside control; it also limited the capacity to organize and carry out complex projects independently. This lack of decision-making ability slowed down the organization, making it highly dependent on leadership, at the risk of becoming bottlenecked in the decision-making chain.

The organization established as its key objective replacing values and behaviors from the old 'cowboy' mentality (Gouldner, 1957) where people worked independently in their own research endeavors related to their particular academic disciplines, to a collaborative approach with values anchored in interdependence and engagement in interdisciplinary undertakings around a wide-ranging notion of scientific work closely associated with delivery to stakeholders.

Specialists in a variety of fields were purposely incorporated in a way that reflected the richness and diversity of HumScience's specialty, creating opportunities for cross-disciplinary research. The 
broadening of academic research areas to include a multilevel, multidisciplinary approach was expected to enhance scientific results by creating a space for new ways of collaboration and learning partnerships. Yet, multidisciplinary work required new attitudes, values and behaviors (Jackson, 1996), which might clash with most standard notions of work in such bureaucratic organizations and therefore call for new organizational arrangements. In this respect, the organization struggled to adapt its practices to scientific innovation by means of fostering a new collaborative culture (Heckscher and Adler, 2006). This kind of innovation, which affected scientific work, had a direct impact on the nature of scientists' work role.

The following sections provide four valuable insights into explaining readiness and resistance to change.

\section{Devising an organizational mission}

Moving toward a new way of working called for a fundamental reappraisal of the roles of everyone involved. One critical aspect, the need to redefine the notion of results, or individual value creation, was a salient issue in interviews and informal conversations held with senior employees, associates and young researchers; this notion was tied to research excellence and concrete models of achievement and success. There was agreement among organizational members that they were lacking a clear sense of the 'customer' or 'service user/consumer' as researchers were managed by the standard norms of basic scientific work. The development of a sense of unified purpose and a strategic orientation around various stakeholders, namely the scientific world, institutional and political actors, commercial partners and society at large, was deemed vital but underdeveloped.

All individuals participated in several discussions to formulate a jointly developed strategic mission for HumScience. The mission had the threefold goal of setting long-term organizational objectives, redirecting scientists' attention from a hierarchical organization where disciplines have a tendency to work in 'silos' into a collaborative, interdisciplinary research setting and defining key stakeholders, and 
to foster a dynamic, service-oriented organization. Everyone participated and was involved in a process of reciprocal influence, in which they attempted to extend their influence and to shape organizational roles. As a result, a broader focus on stakeholder identification and salience, as resource providers to or dependents of the PROs - in other words, to whom and to what scientists must pay attention - was praised by employees at HumScience. It was expected to foster cohesiveness toward a concept of scientific work as dynamic and closely associated with delivery to stakeholders.

\section{Defining role boundaries}

As multidisciplinary work grew more complex, and as it depended on a collective endeavor to engage in more interdisciplinary undertakings, the search for alternative models of organizing work became critical for a public service of this kind. In this respect, the organization struggled to adapt its practices to scientific innovation by means of fostering a new collaborative culture in a way that attributed less value to "doing a good job" or "achieving the defined objectives" and lavished highest praise for people who were able to look beyond their specific roles and do whatever was needed to advance the common purpose, as stated by Adler and colleagues (2010). This kind of innovation, which affected scientific work, was meant to impact directly on the nature of scientists' work role identity. New work roles meant greater individual accountability toward a common purpose by establishing collaborative relationships tied to effective cross-disciplinary information sharing and continuous learning. Emphasis on knowledge and collaboration called for a redefinition of the traditional role of researchers in the workplace, along with greater emphasis on teamwork and contribution to shared purposes as critical competitive capabilities (Clegg et al., 2011; Heckscher, 2007).

Based on subjective perceptions and preferences, researchers attempted to coordinate their behaviors and come to jointly define what constituted a researcher's role in the context of a collaborative research organization. To a great extent, they were required to unlearn established beliefs and rules in 
order to be receptive to new roles and their required knowledge base. Early in 2009, several senior scientists drew attention to the complexity and ambiguity of cultural transformation. They often worried about the subjectivity involved in promoting a collaborative work environment and the fact that certain researchers would perform at a lower level by not being able to adjust to their new work roles adequately.

\section{Confronting challenges in learning their new work role}

New work roles required all researchers to make the collaborative perspective part of the organizational culture. An important aspect of the difficulty of transitioning toward a collaborative culture was the presence of bureaucratic rules - the degree to which the behavior of scientists was subject to organizational control. Under the premise that changes in organizational culture would promote organizational vision among researchers, leadership focused on reform culture first and attempted to change formal work practices later. Such changes might have consequences in a broad array of management practices: performance evaluation, compensation, and career. However, these transformations conflicted with HumScience's hierarchical, bureaucratic norms, procedures, and reward structures. Younger, non-tenured researchers were prone to substitute the bureaucratic organizational system by more corporate-driven practices: management by objectives, individual rewards and career paths_-particularly for younger generations of scientists. External pressure also played against a system based on a rigid professional path for civil servants, with a reduced number of hierarchical layers, and standardized compensation and evaluation practices. However, more senior, tenured researchers felt threatened by the consequences of implementing managerial practices, in the form of higher competition for resources and rewards and cloudier advancement paths.

Symbolic-interactionist approaches to role transition theory have explored the interrelations between cognitive/behavioral factors and introduction of organizational transformations, and a number 
of recent studies have explored the interplay between cultural change and adoption of performance appraisal and reward systems in government institutions (e.g., Azzone and Palermo, 2011). This is a major concern in traditional PROs too (Hansson, 2006; Rafols et al., 2012). At HumScience, there was a debate regarding governance and control. Particularly, researchers were concerned and confused about the assessment of scientific performance and interdisciplinarity. Thus, whereas coordination and control in the traditional hierarchical organization revolved around standard procedures and reliability-focused practices, in the resulting collaborative organization it was expected to be based more on exploration and on learning-focused practices. As HumScience developed a collaborative infrastructure, the logic of command-and-control seemed ill fitted to organizational requirements such as collaboration, dealing with uncertainty or embracing multiple decision-making variability, yet introducing changes in assessment remained controversial and exhibited no consensus on appropriate frameworks. Researchers feared the impact of bibliometric assessments measuring scientific performance would have in the management of the organization and on the behavior of employees. Specifically, they highlighted fundamental challenges regarding integrating across disciplines, encouraging risk-taking, and rewarding long-term planning and performance. Several researchers suggested that HumScience, in its pursuit of a collaborative culture, should place strong emphasis on aligning the standard bureaucratic interest of individual performance with the need to build collaborative work relationships and shared professional values as it sought to place greater emphasis on common purpose and outcomes in order to thrive.

\section{Negotiating an unfamiliar culture}

Under the collaborative work environment, researchers reacted to redesigned researcher work. A defining feature of the novel organizational culture that received considerable emphasis in researchers' responses was the necessity of tying traditional and new work roles to the central functions of researchpublishing and learning. Behavior is defined by a reflective, socially understood meaning of both the 
internal and external incentives and expectations attached to a professional self-identity (Adler et al., 2008). That way, increased incentives for applied research may lead scientists to work on more productive or complementary research areas (Simpson and Powell, 1999). Researchers at HumScience were encouraged to produce research that was socio-economically relevant, applied and preferably useful to industry. These market (i.e., economic) incentives clashed with non-market incentives related to an advance in knowledge and priority of discovery. As Merton (1973) argued, the spirit of science is "communitarian" regarding access to the knowledge and technique it creates. For researchers at HumScience, reputation and professional development were tightly bound to scientific excellence, measured in terms of peer recognition.

The tension between institutionalization of new roles and negotiation by scientists constituted a strong dilemma at HumScience (Ilgen and Hollenbeck, 1991). Rather than fixed and imposed by changing demands, most senior researchers viewed scientists' role as a negotiable shared understanding closely tied to their professional identity at large. The various work role requirements were discussed by different organizational members. Open discussions focused on how researchers engage in a new role rather than on how they disengage from their previous role. Work role transition and identity processes amongst scientists revealed tensions between a willingness for change and an implicit desire to maintain the status quo. As a result, researchers went from personal involvement during the first phases of the innovation initiative to exhibiting increased pessimism toward the new culture's values of multidisciplinarity and contribution. One senior researcher commented: "Let's agree on this: who does not want to work in a more collaborative place? Who does not want to work with and learn from other highly reputated [sic] scientists? Question is: how are we to accomplish all these things without the commitment and action of everybody involved to get this going?" Similarly, a young, recently appointed 
researcher lamented: "How will change initiatives prevail over detachment if leadership does not have the ability to control nor the power to influence our research culture?"

\section{Discussion}

In public research centers and organizations, individual contribution depends increasingly on collective endeavor, which depends on other scientists' values and choices (Jones et al., 2008), thereby making the search for collaborative models of organization critical for this type of public services. This seems especially acute in bureaucratized but particularly complex knowledge settings, such as PROs. These organizations play a key role in the development of science and technology in most western countries. In line with the public/private dichotomy and the increased blurring of the traditional boundaries between the public and private spheres, PROs struggle to adapt their organizational models in order to refocus towards more dynamic, service-oriented organizations, with a broader focus on stakeholders - those who provide resources to the organization and are dependent on it. With this study, I suggest that certain mechanisms borrowed from private organizations, such as collaborative organizational culture, can serve PROs as important enablers of transitions between different stages of the organizational adaptation process. However, this evolution is difficult for scientists, and the outcome is unsure.

Anchored in symbolic-interactionist role transition theory, public researchers' responses to demands for greater efficiency and accountability for service-oriented and use-inspired research provide a window into the impact of organizational innovations on their work. The research carried out at HumScience raises a number of theoretical issues. The difficulties experienced by public scientists in the transition toward a collaborative culture included devising an organizational mission, defining role boundaries, confronting challenges in learning their new work role, and negotiating an unfamiliar culture. The results indicate that scientists varied in the degree to which they accepted novel 
collaborative culture norms and values, and that by remaining unaware of people's dilemmas, the organization risked failure in implementing the changes despite the innovation having been deemed appropriate for research centers. Because of their fundamental role in the success of PROs, realizing how individual employees develop an understanding and react to changes in work roles is a critical endeavor for both researchers and practitioners alike. Scientists find the transition from one role to another difficult, since incentives and control remain at odds, and management practices are hardly translated into the new organizational culture. Scientific organizations must rely on new infrastructure that breaks with deeply ingrained organizational routines.

It appears that pursuing collaborative culture may represent an answer to the increasing need for continuous sustainable innovation and adaptability in PROs. However, there are also limits to the reform of organizational culture (Erhardt et al. 2009). The transition of PROs toward post-bureaucratic or collaborative types of organization present intrinsic difficulties, particularly those associated with changes in attitudes, values and behaviors present in these organizations. For collaborative organizational culture to take place in highly bureaucratic PROs, it would appear that management and administrative practices should be integrated throughout the process. Without clear direction and purpose, acceptance of administrative innovations taken from private sector models is not likely to occur within the boundaries of a formal scientific organization with its restricting rigidities and bureaucracies (Josserand et al., 2006; McCabe, 2010; McNulty and Ferlie, 2004). Scientists in HumScience first needed to unlearn established beliefs and rules in order to be receptive to new roles and their required knowledge base. 


\section{References}

Adler, P., Heckscher, C. and Prusak, L. (2010), "Building collaborative enterprise", Harvard Business Review, Vol. 89 No. 7-8, pp. 94-101.

Adler, P., Kwon, S.W. and Heckscher C. (2008), "Professional work: The emergence of collaborative community", Organization Science, Vol. 19 No. 2, pp. 359-376.

Armbruster, H., Bikfalvi, A., Kinkel, S. \& Lay, G. (2008), "Organizational innovation: The challenge of measuring non-technical innovation in large-scale surveys”, Technovation, Vol. 28 No. 10, pp. 644-657.

Ashforth, B. (2000), Role Transitions in Organizational Life: An Identity-Based Perspective, Lawrence Erlbaum, New Jersey.

Azzone, G. and Palermo, T. (2011), "Adopting performance appraisal and reward systems: A qualitative analysis of public sector organisational change", Journal of Organizational Change Management, Vol. 24 No. 1, pp. 90111.

Beer M. (2011), "Developing an effective organization: Intervention method, empirical evidence, and theory", in Shani, A. B., Woodman, R.W. and Pasmore, W.A. (Ed.), Research in Organizational Change and Development, Vol. 19, pp.1-54.

Birkinshaw, J., Hamel, G. and Mol, M. J. (2008), "Management innovation”, Academy of Management Review, Vol. 33 No. 4, pp. 825-845.

Bozeman, B. (1987), All Organizations Are Public: Comparing Public and Private Organizations, Beard Books, Washington D.C.

Bozeman, B. and Boardman, P. C. (2003), Managing the New Multipurpose, Multidiscipline University Research Centers: Institutional Innovation in the Academic Community, IBM Center for the Business of Government, Arlington, VA.

Bozeman, B. and Crow; M. (1990), "The environments of US R\&D laboratories: political and market influences", Policy Sciences, Vol. 23 No. 1, pp. 25-56.

Brunton M. and Matheny, J. (2009), "Divergent acceptance of change in a public health organization", Journal of Organizational Change Management, Vol. 22 No. 6, pp. 600-619.

Charon, J. M. (2009), Symbolic interactionism: An introduction, an interpretation, an integration, Prentice-Hall, Englewood Cliffs, NJ

Clanon, J. (1999), "Organizational transformation from the inside out: Reinventing the MIT Center for Organizational Learning", Learning Organization, The, Vol. 6 No. 4, pp. 147 - 156

Clegg, S., Harris M. and Höpfl, H. (2011), Managing Modernity: Beyond Bureaucracy?, Oxford: Oxford University Press.

Crow, M. and Bozeman, B. (1998), Limited by Design. R\&D Laboratories in the U.S. National Innovation System, Columbia University Press, New York.

Cruz-Castro, L., Sanz-Menendez, L. and Martinez, C. (2012), "Research centers in transition: patterns of convergence and diversity", The Journal of Technology Transfer, Vol. 37 No. 1, pp. 18-42.

Daft, R.L. and Weick, K.E. (1984), "Toward a model of organizations as interpretation systems." Academy of Management Review, Vol. 9 No. 2, pp. 284-295. 
Damanpour, F. (1991), "Organizational innovation: A meta-analysis of effects of determinants and moderators", Academy of Management Journal, Vol. 34 No. 3, pp. 555-590.

Damanpour, F., Walker R. and Avellaneda, C. (2009), "Combinative effects of innovation types and organizational performance: A longitudinal study of service organizations", Journal of Management Studies, Vol. 46 No. 4, pp. 650-675.

Erhardt, N., Martin-Rios, C. and Way, S. (2009), "From bureaucratic forms towards team-based knowledge work systems: Implications for human resource management", International Journal of Collaborative Enterprise, Vol. 1 No. 2, pp. 160-179.

Ferlie, E., Ashburner, L., Fitzgerald, L. and Pettigrew, A. (1996), New Public Management in Action. Oxford University Press, Oxford.

Fernandez, S. and Rainey, H. G. (2006), "Managing successful organizational change in the public sector”, Public Administration Review, Vol. 66 No. 2, pp. 168-176.

Gouldner, A. W. (1957), "Cosmopolitans and locals: Toward an analysis of latent social roles", Administrative Science Quarterly, Vol. 2 No. 3, pp. 281-306.

Hatch, M.J. and Yanow, D. (2002), "Organizational studies as an interpretive science", In Knudsen C. and Tsoukas H. (Ed.), The Oxford Handbook of Organization Theory, Oxford University Press, Oxford, pp. 63-87.

Hansson, F. (2006), "Organizational use of evaluations governance and control in research evaluation", Evaluation, Vol. 12 No. 2, pp. 159-178.

Heckscher, C. (2007), The Collaborative Enterprise, Yale University Press, New Haven, CT.

Heckscher, C. and Adler, P. (2006), The Corporation as a Collaborative Community: Organization in the Knowledge-Based Economy. Oxford University Press, Oxford.

Heckscher, C. and Martin-Rios, C. (2013), "Looking back, moving forward: Toward collaborative universities", Journal of Management Inquiry, Vol. 22 No. 1, pp. 136-139.

Hernes, T. and Maitlis, S. (2010), Process, sensemaking, and organizing. Oxford University Press, Oxford.

Hipp, C. and Grupp, H. (2005), "Innovation in the service sector: The demand for service-specific innovation measurement concepts and typologies", Research Policy, Vol. 34 No. 4, pp. 517-535.

Ilgen, D. R. and Hollenbeck, J. R. (1991), "The structure of work: Job design and roles", Handbook of Industrial and Organizational Psychology, Vol. 2, pp. 165-207.

Jackson, S. E. (1996), The consequences of diversity in multi-disciplinary work teams, West, M.A., Handbook of Work Group Psychology, Wiley, Chichester, UK, pp. 53-76

Jones, B., Wuchty, S. and Uzzi, B. (2008), "Multi-university research teams: Shifting impact, geography, and stratification in science", Science, Vol. 322 No. 5905, pp. 1259-1262.

Josserand, E., Teo S. and Clegg, S. (2006), "From bureaucratic to post-bureaucratic: the difficulties of transition", Journal of Organizational Change Management, Vol. 19 No. 1, pp. 54-64.

Langley, A. (1999), "Strategies for theorizing from process data", Academy of Management Review, Vol. 24 No. 4, pp. 691-710. 
Langley, A., Smallman, C., Tsoukas, H. and Van de Ven, A. H. (2013), "Process studies of change in organization and management: unveiling temporality, activity, and flow", Academy of Management Journal, Vol. 56 No. 1, pp. 1-13.

Maitlis, S. (2005), "The social processes of organizational sensemaking", Academy of Management Journal, Vol. 48 No. 1, pp. 21-49.

Mallon, M., Duberley, J. and Cohen, L. (2005), "Careers in public sector science: Orientations and implications", $R \& D$ Management, Vol. 35 No. 4, pp. 395-407.

Martin-Rios, C. (2014), "Why do firms seek to share human resource management knowledge? The importance of inter-firm networks", Journal of Business Research, Vol. 67 No. 2, pp. 190-199.

Martin-Rios, C. (in press), "Innovation in organizational control systems: Toward greater accountability", International Journal of Business Performance Management.

Martin-Rios, C. and Heckscher, C. (2014), "Rekindling university organizational model", Revista Internacional de Sociología, Vol. 72 No. 1, pp. 203- 248.

Martinez, C., Azagra-Caro, J. and Maraut, S. (2013), "Academic investors, scientific impact and the institutionalization of Pasteur's quadrant in Spain", Industry and Innovation, Vol. 20 No. 5, pp. 438-455.

McCabe M. (2010), "Taking the long view: A cultural analysis of memory as resisting and facilitating organizational change", Journal of Organizational Change Management, Vol. 23 No. 3, pp.230-250.

McNulty, T. and Ferlie, E. (2004), "Process transformation: Limitations to radical organizational change within public service organizations", Organization Studies, Vol. 25 No. 8, pp. 1389-1412.

Merton, R.K. (1973), The Sociology of Science: Theoretical and Empirical Investigations. University of Chicago Press, Chicago.

Miles, M.B. and Huberman, A.M. (1994), Qualitative Data Analysis: An Expanded Sourcebook, Sage, Thousand Oaks, CA.

Nelson, R. R. (1990), "Capitalism as an engine of progress", Research Policy, Vol. 19, pp. 193-214.

Nicholson, N. (1984), "A theory of work role transitions", Administrative Science Quarterly, Vol. 29 No. 2, pp. 172-191.

OECD. (2005), "Oslo Manual. Proposed guidelines for collecting and interpreting technological innovation data", available at: http://www.ttgv.org.tr/UserFiles/File/OSLO-EN.pdf [accessed April 2015]

OECD (2011), "Actor Brief on Public Research Organizations (PROs)", available at: http://www.oecd.org/innovation/policyplatform/48136051.pdf [accessed April 2015]

Parga, E., Martin-Rios, C., and Criado, F. (2013), "Organizational and management innovation as a driving force of business renewal", Journal of Technology Management Innovation, Vol. 8, No 2, pp. 132-143.

Perry, J. L and Rainey, H. G. (1988), "The Public-Private Distinctions in Organization Theory", Academy of Management Review, Vol.13 No. 2, pp. 182-201.

Rafols, I., Leydesdorff, L., O’Hare, A., Nightingale, P. and Stirling, A. (2012), "How journal rankings can suppress interdisciplinary research: A comparison between innovation studies and business \& management", Research Policy, Vol. 41 No.7, pp. 1262-1282. 
Rainey, H. G. and Bozeman, B. (2000), "Comparing Public and Private Organizations. Empirical research and the Power of A Priori", Journal of Public Administration Research and Theory, Vol.10 No. 2, pp. 447-469.

Salge, T. O. (2011). A behavioral model of innovative search: Evidence from public hospital services. Journal of Public Administration Research and Theory, Vol. 21 No. 1, pp. 181-210.

Sanz-Menendez, L. and Cruz-Castro, L. (2003), "Coping with environmental pressures: public research organisations responses to funding crises", Research Policy, Vol. 32 No. 8, pp. 1293-1308.

Simpson, B. and Powell, M. (1999), "Designing research organizations for science innovation", Long Range Planning, Vol. 32 No. 4, pp. 441-451.

Stensaker, I. and Falkenberg, J. (2007), "Making sense of different responses to corporate change", Human Relations, Vol. 60 No. 1, pp. 137-177.

Strauss A. and Corbin, J. (1998), Basics of Qualitative Research. Sage, Thousand Oaks, CA.

Van de Ven A. and Huber, G.P. (1990), "Longitudinal field research methods for studying the process of innovation", Organization Science, Vol. 1 No. 3, pp. 213-219.

Weick, K.E. (1993), "The collapse of sensemaking in organizations: The Mann Gulch disaster", Administrative Science Quarterly, pp. 628-652.

Weick, K.E., Sutcliffe, K.M. and Obstfeld, D. (2005), "Organizing and the process of sensemaking", Organization Science, Vol. 16 No. 4, pp. 409-421.

Yin, R. K. (1994), Case Study Research: Design and Methods. Sage, Newbury Park, CA. 


\section{TABLES AND FIGURES}

Table 1. Coding examples of organizational members' sensemaking activities and work role transition (28 counts)

\begin{tabular}{|l|l|}
\hline \multicolumn{2}{|c|}{ Sensemaking of changes in work roles } \\
\hline \multicolumn{1}{|c|}{$\begin{array}{c}\text { Work role challenges } \\
\text { (Difficulties in transitioning to new } \\
\text { work roles) }\end{array}$} & \multicolumn{1}{|c|}{$\begin{array}{c}\text { Collaborative culture } \\
\text { (Negotiating an unfamiliar culture) }\end{array}$} \\
\hline $\begin{array}{l}\text { Successful transitioning (7) } \\
\text { (e.g. "We need a radically new research } \\
\text { mission.") }\end{array}$ & $\begin{array}{l}\text { Reflection (6) } \\
\text { (e.g. "between new roles and previous } \\
\text { work requirements.") }\end{array}$ \\
\hline $\begin{array}{l}\text { Bureaucratic rules (4) } \\
\text { (e.g. "With all our bureaucratic rules } \\
\text { and regulations, firing scientist- } \\
\text { bureaucrats, even for incompetence, is } \\
\text { very difficult.") }\end{array}$ & $\begin{array}{l}\text { Consensual decisions (4) } \\
\text { (e.g. "our professional identity is } \\
\text { constructed through our own ideas of } \\
\text { 'what to be' and 'how to be.') }\end{array}$ \\
\hline $\begin{array}{l}\text { Bureaucratic work rules (3) } \\
\text { (e.g. "We are meeting new work } \\
\text { standards without creating the proper } \\
\begin{array}{l}\text { conditions for their achievement. It isn't } \\
\text { clearly much of an agreement to start } \\
\text { with.") }\end{array}\end{array}$ & $\begin{array}{l}\text { Tension (4) } \\
\text { (e.g. "I don't necessarily agree with the } \\
\text { new researcher profiling here.") }\end{array}$ \\
\hline
\end{tabular}

